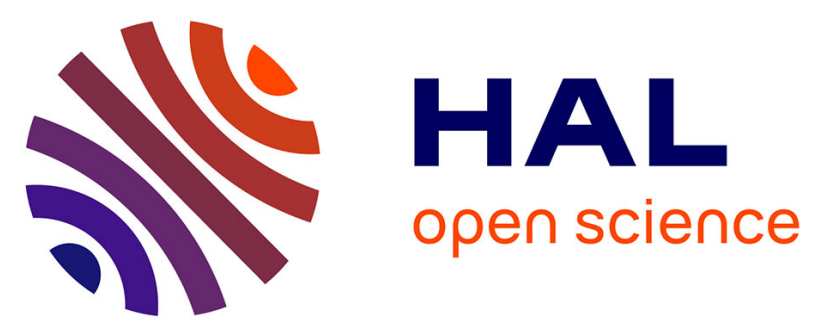

\title{
The cost effectiveness of integrated care for people living with HIV including antiretroviral treatment in a primary health care centre in Bujumbura, Burundi
}

Adrien Renaud, Olivier Basenya, Nicolas de Borman, Isaline Greindl, Gesine Meyer-Rath

\section{To cite this version:}

Adrien Renaud, Olivier Basenya, Nicolas de Borman, Isaline Greindl, Gesine Meyer-Rath. The cost effectiveness of integrated care for people living with HIV including antiretroviral treatment in a primary health care centre in Bujumbura, Burundi. AIDS Care, 2009, 21 (11), pp.1388-1394. 10.1080/09540120902884042 . hal-00545378

\section{HAL Id: hal-00545378 https://hal.science/hal-00545378}

Submitted on 10 Dec 2010

HAL is a multi-disciplinary open access archive for the deposit and dissemination of scientific research documents, whether they are published or not. The documents may come from teaching and research institutions in France or abroad, or from public or private research centers.
L'archive ouverte pluridisciplinaire HAL, est destinée au dépôt et à la diffusion de documents scientifiques de niveau recherche, publiés ou non, émanant des établissements d'enseignement et de recherche français ou étrangers, des laboratoires publics ou privés. 

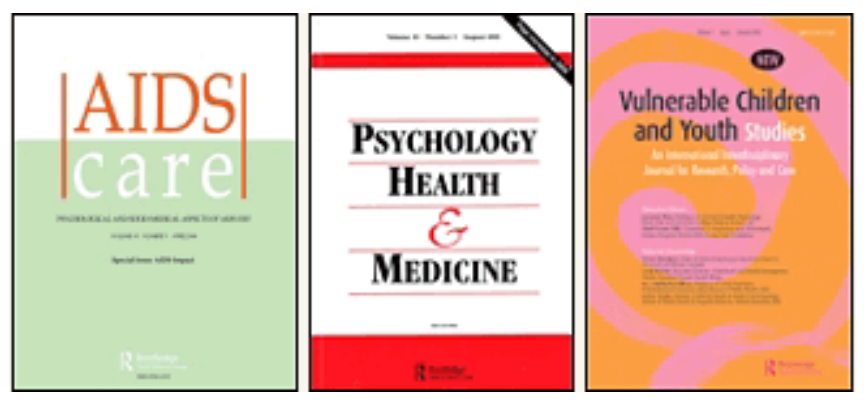

The cost effectiveness of integrated care for people living with HIV including antiretroviral treatment in a primary health care centre in Bujumbura, Burundi

\begin{tabular}{|r|l|}
\hline Journal: & $\begin{array}{l}\text { AIDS Care - Psychology, Health \& Medicine - Vulnerable Children } \\
\text { and Youth Studies }\end{array}$ \\
\hline Manuscript ID: & AC-2009-01-0023.R1 \\
\hline Journal Selection: & AIDS Care \\
\hline Keywords: & $\begin{array}{l}\text { Primary Health care, Cost effectiveness, Antiretroviral treatment, } \\
\text { Integrated care }\end{array}$ \\
\hline \multicolumn{2}{|l}{} \\
\hline
\end{tabular}

\section{(s) ScholarONE" \\ Manuscript Central}




\section{The cost effectiveness of integrated care for people living with HIV including antiretroviral treatment in a primary health care centre in Bujumbura, Burundi}

\section{Abstract}

The incremental cost effectiveness of an integrated care package (i.e. medical care including antiretroviral therapy and other services such as psychological and social support) for people living with HIV/AIDS was calculated in a not-for-profit primary health care centre in Bujumbura run by Society of Women Against Aids (SWAA) -Burundi, an African nongovernmental organisation (NGO).

Results are expressed as cost-effectiveness ratio 2007, constant US\$ per Disability-Adjusted Life Year (DALY) averted. Unit costs are estimated from the NGO's accounting data and activity reports, healthcare utilisation is estimated from the medical records of a cohort of 149 patients. Effectiveness is modelled on the survival of this cohort, using standard calculation methods.

The incremental cost of integrated care for people living with HIV/AIDS in the Bujumbura health centre of SWAA-Burundi is 258 US\$ per DALY averted.

The package of care provided by SWAA-Burundi is therefore a very cost-effective intervention in comparison with other interventions against HIV/AIDS that include antiretroviral therapy (ART). It is however, less cost-effective than other types of interventions against HIV/AIDS, such as preventive activities. 
The cost effectiveness of integrated care for people living with HIV including antiretroviral treatment in a primary health care centre in Bujumbura, Burundi

\section{Key words}

Primary health care, cost effectiveness, ART treatment, integrated care. 


\section{Introduction}

HIV/AIDS represents one fifth of the burden of disease in Burundi (World Health Organization, 2004), and therefore constitutes the main burden of disease for the country. Since the beginning of the epidemic, Burundian non-governmental organisations have been playing a leading role in the fight against the virus. They were the ones who started the fight against discrimination against people living with HIV, and who started providing these people with medical care. In 2003, they were also the first to be able to deliver antiretroviral therapy (ART). Their role is still essential today, since out of the 10,865 people receiving ART in Burundi in 2007, $65 \%$ were treated in not-for-profit primary health care facilities (Conseil National de Lutte contre le SIDA, 2008).

ART can impose a heavy burden on the patient: the need for a strict drug schedule and regular outpatient visits and laboratory tests, as well as the risk of developing side effects and Immune Reconstitution Inflammatory Syndrome (IRIS), are some of the reasons why some patients have difficulties to fully adhere to the treatment. Proximity between the health workers and the patient can therefore be a major asset for successful treatment.

Burundian NGOs take full advantage of this proximity asset thanks to two distinctive features: first, care is given in primary health care facilities, which favours a more personal link with patients. Secondly, these health facilities deliver integrated care for people living with HIV, which means that they provide social and psychological services in addition to medical ones. This social and psychological support is meant to facilitate adherence to ART with services such as home visits, patient support groups, income-generating activities, cooking workshops, etc. There is general agreement now that primary health care facilities 

primary health care centre in Bujumbura, Burundi

deliver good quality care for people living with HIV/AIDS in developing countries, especially in the face of scarce resources (Coetzee et al, 2004).

Studies on the cost effectiveness of ART in low and middle-income countries however yield very different results, ranging from as low as 350 US\$ per Disability-Adjusted Life Year averted (Marseille, Hofmann \& Kahn, 2002) to as much as 2,010 international dollars per DALY averted (Hogan, Baltussen, Hayashi, Lauer \& Salomon, 2005). This is due to, among other reasons, the constant downward trend in antiretroviral drug prices in low and middle-income countries, but also to diverging assumptions made by researchers (inter alia, regarding types of cost included and excluded, discounting rates, exchange rates).

This study aims at calculating the incremental cost effectiveness of ART delivered by the Bujumbura health centre of the Society for Women against AIDS in Africa-Burundi (SWAABurundi), an African NGO which is present in more than 40 countries, and whose headquarters are located in Dakar, Senegal. The facility we studied is a primary health centre that delivers care only to people living with HIV, and where ART has been has been delivered since February 2003. With 668 people on treatment in 2007, this health centre constitutes the fourth biggest ART clinic in the country (Conseil National de Lutte contre le SIDA, 2008).

\section{Methodology}

This analysis describes the incremental cost effectiveness of ART provision by the Bujumbura clinic of SWAA-Burundi, between February 2003 and February 2008, from a healthcare provider perspective.

\section{Sample}

The analysis included all 149 patients initiated on antiretroviral treatment from February 1. 2003 to April 21. 2004, regardless of whether they were still being followed up at SWAA, 
The cost effectiveness of integrated care for people living with HIV including antiretroviral treatment in a primary health care centre in Bujumbura, Burundi

had been referred to other facilities, were lost to follow-up, or had died. 21 patients whose medical records were inconclusive as to whether patients had benefited from ART (only one physician visit, or only one laboratory test) were excluded from the analysis. The mean treatment duration among patients in the cohort was 3.6 years and the female/male ratio was 4/1 (table1). Most patients (128 out of 149) were between 30 and 59 years old (table 2).

Healthcare utilisation frequencies were abstracted by a team of experienced physicians through a retrospective analysis of the medical records of the 149 patient of the cohort. EpiData 3.0 software was used for data input, and EpiInfo 6.04 software for analysis.

\section{Estimation of unit cost}

We identified 11 cost items. Unit costs for the ones that are done in-house could be calculated by summing up capital, recurrent and overhead costs borne for them by the facility in year 2007. Overhead costs allocation was based on the wage bill.

This was the case for 7 cost items:

- Out-patient visit.

- Pharmacy: Only the costs of retailer storage and distribution are included here, drug prices are included under drug costs below.

- Laboratory: Only some of the tests such as blood counts or liver function tests are done in-house. Viral load (VL) and CD4 count are contracted out and considered below.

- Voluntary counselling and testing for HIV (VCT).

- Adherence counselling. 

primary health care centre in Bujumbura, Burundi

- Psychological and social support (excluding food support): home visits, hospital visits and patient support groups

- Food support: distribution of monthly food parcels with basic items such as flour, corn, beans and green peas.

Data on day hospitalisation costs was incomplete in the medical records. We therefore had to use the average number of days spent in the day hospital by all SWAA-Burundi patients (data taken from the association's annual report).

Some of the services are delivered by providers outside the NGO. We also had to use proxies to assess their unit cost. This has been the case for:

- External laboratory: VL and CD4 count.

- External hospitalisations.

- Drug costs.

The unit cost for VL and CD4 count tests has been calculated by summing the cost of reagents provided to laboratories by the National Council for the Fight against AIDS (Conseil National de Lutte contre le SIDA, CNLS) through calls for tender and the cost of laboratory materials. The latter were calculated according to data gathered at the National Public Health Institute (Institut National de Santé Publique, INSP). For these costs, we only included recurrent costs and varied these in sensitivity analyses.

Hospitalization costs were estimated from the annual amount paid by the CNLS on hospitalization divided by the number of patients on ART in the country. This subsidy is meant to reimburse hospitals for all costs incurred by hospitals to deliver care to patients on ART.

The data available at the CNLS indeed did not allow us to calculate the unit cost of one hospitalization day and the utilisation frequencies. 
The cost effectiveness of integrated care for people living with HIV including antiretroviral treatment in a primary health care centre in Bujumbura, Burundi

We used three sources to collect drug prices:

- Where available, we used drug prices available at the Burundian Central Drug Purchasing Body (Centrale d'Achat de Médicaments Essentiels du Burundi, CAMEBU).

- When prices were not available there, we used the prices obtained by CNLS through its calls for tender.

- When prices were not available from either source, we used the prices of a large private pharmacy y in Bujumbura.

All costs are presented at 2007 constant prices. Since all cost sources were for year 2007, except antiretroviral drug costs, adjustment for inflation was needed only for the latter. International Monetary Fund inflation figures for Burundi were used (International Monetary Fund, 2008). Exchange rate in this study is 1 US $\$=1067,2$ FBU (July 1. 2007)

\section{Estimation of survival}

Effectiveness of ART treatment at SWAA-Burundi has been analysed by comparing survival of the patients included in the treatment cohort with the survival of a modelled control cohort with patients that would not have received any treatment.

The survival of patients in our sample cohort has been estimated from the data recorded in SWAA-Burundi's registries, whereas the survival of the control cohort has been modelled on data from Joint United Nations Programme's (UNAIDS) last epidemiological update: In the absence of ART, the average duration between ART eligibility (as defined by a CD4 count of $<200$ cells/ $\mu 1$ or WHO stage 4) and death is estimated to be three years (Joint United Nations Programme on HIV/AIDS, 2007). A recent review of the survival of HIV-positive patients in several African countries found that survival curves are close to linear, except for the extremes (Todd et al, 2007). We estimated therefore that between ART eligibility and death, 

primary health care centre in Bujumbura, Burundi

the survival curve of patients who did not receive any treatment is linearly decreasing with an average duration of three years, and that all patients were dead after six years observation.

For both cohorts, the number DALYs lost because of HIV was estimated according to the standard formula (Murray, 1996). Reference life expectancy to calculate Years of Life Lost (YLL) was set to Burundian rather than international standards. The disability weight to calculate Years of Life lived with Disability (YLDs) was 0,186 (Lopez, Mathers, Ezzati, Jamison \& Murray, 1996). The discount rate was set to $3 \%(r=0,03)$ and no age weights were used $(\mathrm{K}=0)$.

\section{Estimation of cost effectiveness}

The number of DALYs averted by the intervention is the difference between the number of DALYs lost because of HIV in the modelled control cohort and the number of DALY lost because of HIV in the sample cohort. Since the intervention is compared to the absence of ART, the cost of the alternate scenario is zero and the cost of the intervention is the cost of ART provided by SWAA-Burundi. The cost effectiveness of the package provided by SWAA-Burundi is the cost of the provision of the package during the observation period divided by the number of DALYs it averted.

\section{Results}

\section{Estimation unit cost}

Average annual costs for cost items that could be estimated according to capital, recurrent and overhead costs borne by the NGO amount to 429 US\$ per patient (table 3).

As mentioned earlier, hospitalisation costs had to be estimated from national averages. According to CNLS data, the average annual per patient cost for hospitalisations is 16 US\$ for patients on ART. 
The cost effectiveness of integrated care for people living with HIV including antiretroviral treatment in a primary health care centre in Bujumbura, Burundi

The cost of CD4 count and VL tests have been estimated from external data and amount respectively to 19 and 14 US\$ per patient and per year (table 4).More than $80 \%$ of the patients were on first line antiretroviral regimens. Drugs for these first line regimens cost between 83 and 268 US\$ per patient and per year at 2007 prices (table 5). Once adjusted for inflation and for the evolution of drug prices and exchange rates during the observation period, the average antiretroviral drug cost per patient and per year range from 811 US\$ in 2003 to 242 US\$ in 2008 (table 6). Drugs for opportunistic infection (OI) prophylaxis (cotrimoxazole and fluconazole) cost 5 US\$ per patient and per year.

Drugs for the treatment of OIs, ART side effects, and other common co-morbidity cost 12 US\$ per patient and per year (table 7).

Once adjusted for inflation and for the evolution of drug prices and exchange rates during the observation period, total treatment costs ranged from 1,305 US\$ per patient and per year in 2003 to 736 US\$ per patient and per year in 2008 (table 8).

\section{Estimation of survival}

Kaplan Meier analysis was used to estimate the survival of SWAA-Burundi's patients. This analysis shows that the equivalent of $87,5 \%$ of the patients are still alive after 5 years of antiretroviral treatment, while only $15,6 \%$ would have been alive with no treatment (figure 1).

Under our assumptions (3\% discount rate and no age discounting), this survival results in 1,912 DALYs averted for the cohort, which results in 13 DALYs averted per patient (table 9). 
The cost effectiveness of integrated care for people living with HIV including antiretroviral treatment in a primary health care centre in Bujumbura, Burundi

\section{Estimation of cost effectiveness}

The costs calculated above show that the total cost of treating the 149 patients in the sample cohort during the observation period is 493,140 US\$ (2007 constant). Since 1,912 DALYs have been averted during the same period, the cost per DALY averted is 258 US\$.

\section{Sensitivity analysis}

The results of this cost effectiveness analysis rest on a number of important assumptions. One of the main assumptions is that life expectancy after ART eligibility is 3 years in the absence of treatment. When using earlier UNAIDS recommendations, an average life expectancy of 2 years after the point of eligibility (Joint United Nations Programme on HIV/AIDS, 2007), the total number of DALYs averted is 2,077 instead of 1,912 and the cost per DALY averted is 237 US\$ instead of 258 US\$, i.e. $8 \%$ lower. Since the change of the input parameter was $33 \%$, our results are insensitive to the change of this assumption.

We also chose not to weight patients in the sample according to their age in the calculation of YLL $(\mathrm{K}=0)$. Introducing full age weights $(\mathrm{K}=1)$ is expected to increase the number of DALYs lost by both the sample and the control cohort, since most patients are in fully productive years, but it is expected to have a limited impact on the number of DALYs averted by ART, since both cohorts are affected in the same way by the change in the $\mathrm{K}$ parameter. Indeed, introducing full age weights instead of no age weights results in 228 US\$ per DALY averted instead of 258 US\$ per DALY averted, i.e. a $12 \%$ change.

Last, the utilisation frequencies of CD4 counts and VL were below medical standards: 1.07 and 0.53 tests per year respectively instead of 2 and 1 test. Setting the utilisation frequencies to medical standards only slightly affects our results since the cost per DALY averted is then 266 US\$, i.e. 3\% increase. Moreover, as noticed above, we could not integrate capital and overhead costs in the calculation of the unit cost of VL and CD4 counts tests. Doubling the 
The cost effectiveness of integrated care for people living with HIV including antiretroviral treatment in a primary health care centre in Bujumbura, Burundi

unit cost of these tests would result in 3\% higher cost per DALY averted (10\% if adjustment for the undervaluation of unit costs is cumulated with the adjustment for utilisation frequencies).

\section{Discussion}

The cost-effectiveness ratio we find is lower than what has been calculated in other studies on the cost effectiveness of ART in low and middle-income countries. A literature review that included re-calculations in order to allow comparisons (Creese, Floyd, Alban, \& Guinness, 2002) found a cost-effectiveness ratio of ART of 1,100 US\$ per DALY averted at 2000 prices, which amounts to 1,500 US\$ at Burundian 2007 prices. Another review that intentionally made a set of assumptions lowering the cost of ART such as the absence of outpatient visits, laboratory tests, psychological and social support, or second-line drugs (Marseille et al 2002) found a cost-effectiveness ratio for ART of 395 US\$ per DALY averted, which is at Burundian prices the equivalent of 713 US\$ (2007 constant US\$). More recent reviews find lower costs per DALY averted than Creese et al or Marseille et al, but their results are still higher than ours. For example, a WHO-CHOICE study on developing countries based on a transmission model (Hogan et al, 2005), found a cost-effectiveness ratio for ART (using first and second-line drugs) of 2,010 international dollars per DALY saved, which was at Burundian prices the equivalent of 505 US\$ (constant 2007 US\$).

These differences can partly be explained by the decrease in drug prices. For example, although the drug prices used by Creese et al or Marseille et al was low by 2002 standards $^{1}$, it is higher than what could be obtained by the Burundian CNLS during most of our observation

\footnotetext{
$1 \quad$ They use the $350 \$$ per patient per year price the NGO Médecins Sans Frontières obtained from generic manufacturers, in 2001 which amounts to 429 US\$ at 2007 Burundian prices.
} 
The cost effectiveness of integrated care for people living with HIV including antiretroviral treatment in a primary health care centre in Bujumbura, Burundi

period. However, the decreasing drug prices cannot explain all the difference we observe between our results and the ones former studies obtained.

Another explanation can be that although our observation period ranges from 2003 to 2008, we applied 2007 unit costs for all cost items but antiretroviral drugs. We therefore costed the package delivered by SWAA-Burundi (excluding antiretroviral drugs) as if the efficiency of the clinic was as high in 2003 as in 2007 , which might be a cause of undervaluation. But the fact that the cost effectiveness ratio we find is lower than what has been found in the literature might point to the fact that the efficiency of ART provision in Burundi has increased during this period....

We should however also compare our results with the ones found for other types of interventions against HIV/AIDS, and especially with preventive interventions. Marseille et al find that Sexually Transmitted Diseases (STD) control and condom distribution can cost less that 1 US\$ per DALY averted (2 US\$ at Burundian 2007 prices) if targeted to high-risk groups such as sex workers, 13 US\$ per DALY averted (23 US\$ at Burundian 2007 prices) for STD control in general population, 8 US\$ per DALY averted (14 US\$ at Burundian 2007 prices) for blood safety. ART provided by SWAA-Burundi is therefore still much less costeffective than prevention intervention

Comparison between the results of cost effectiveness analyses is generally difficult since most of the time, the methods and assumptions used are either different from one study to another, or not clearly set out (Fox-Rushby \& Hanson, 2001). The cost effectiveness of ART in developing countries makes no exception, and although the cost effectiveness ratio we find is significantly lower than what has been previously published, comparison difficulties should be kept in mind. 
The cost effectiveness of integrated care for people living with HIV including antiretroviral treatment in a primary health care centre in Bujumbura, Burundi

\section{Acknowledgment}

The authors wish to thank the SWAA-Burundi staff members for their cooperation. 


\section{References}

Coetzee, D., Hildebrand, K., Boulle, A., Maartens, G., Louis, F., Labatala, V. et al. (2004). Outcomes after two years of providing antiretroviral treatment in Khayelitsha, South Africa. AIDS, 18, 887-895.

Conseil National de Lutte contre le Sida. (2008). Bilan des réalisations du plan national d'action contre le SIDA, Rapport 2007. Bujumbura, Burundi.

Creese, A., Floyd, K., Alban, A., \& Guinness, L. (2002). Cost-effectiveness of HIV/AIDS interventions in Africa: a systematic review of the evidence. Lancet, 359, 1635-1643.

Fox-Rushby, Ja. \& Hanson, K., (2001). Calculating and presenting disability adjusted life years (DALYs) in cost-effectiveness analysis. Health Policy and Planning; 16(3), 326-331.

Hogan, D.R., Baltussen, R., Hayashi, C., Lauer, J.A. \& Salomon, J.A., (2005). Cost effectiveness analysis of strategies to combat HIV/AIDS in developing countries. BMJ, 331, 14311437.

International Monetary Fund. (2008). World Economic Outllook, April 2008, Housing and Business Cycle. Washington, DC: International Monetary Fund.

Joint United Nations Programme on HIV/AIDS. (2007). Improving parameter estimation, projection methods, uncertainty estimation, and epidemic classification - Report of a meeting of the UNAIDS Reference Group on Estimates, Modelling and Projections held in Prague, Czech Republic, November 29th - December 1st 2006 - Technical report and recommendations. London.

Lopez , A., Mathers, C.D., Ezzati, M., Jamison, D.T. \& Murray, C.J.L. (2006), Global Burden of Disease and Risk Factors. Washington, DC: Oxford University Press and The World Bank. 
The cost effectiveness of integrated care for people living with HIV including antiretroviral treatment in a primary health care centre in Bujumbura, Burundi

Marseille, E., Hofmann, P.B. \& Kahn, J.G. (2002). HIV prevention before HAART in subSaharan Africa. Lancet, 359, 1851-6.

Murray, C.J.L. (1996). Rethinking DALYs. In C.J.L. Murray \& A.D. Lopez (Eds.). The Global Burden of Disease. A comprehensive assessment of mortality and disability for diseases, injuries and risk factors in 1990 and projected to 2020 (pp.1-97). Cambridge, MA: Harvard University Press.

Todd, J., Glynn, J.R., Marston, M., Lutalo, T., Biraroa, S., Mwita, W., et al. (2007). Time from HIV seroconversion to death: a collaborative analysis of eight studies in six low and middle-income countries before highly active antiretroviral therapy. AIDS, 21 (supp/ 6), S55-S63

World Health Organization. (2004). Death and DALY estimates for 2002 by cause for WHO Member States. Retrieved May 15, 2008, from http://www.who.int/entity/healthinfo/statistics/bodgbddeathdalyestimates.xls 
Figure 1 : Survival curves for the SWAA-Burundi cohort and for the control cohort with no treatment

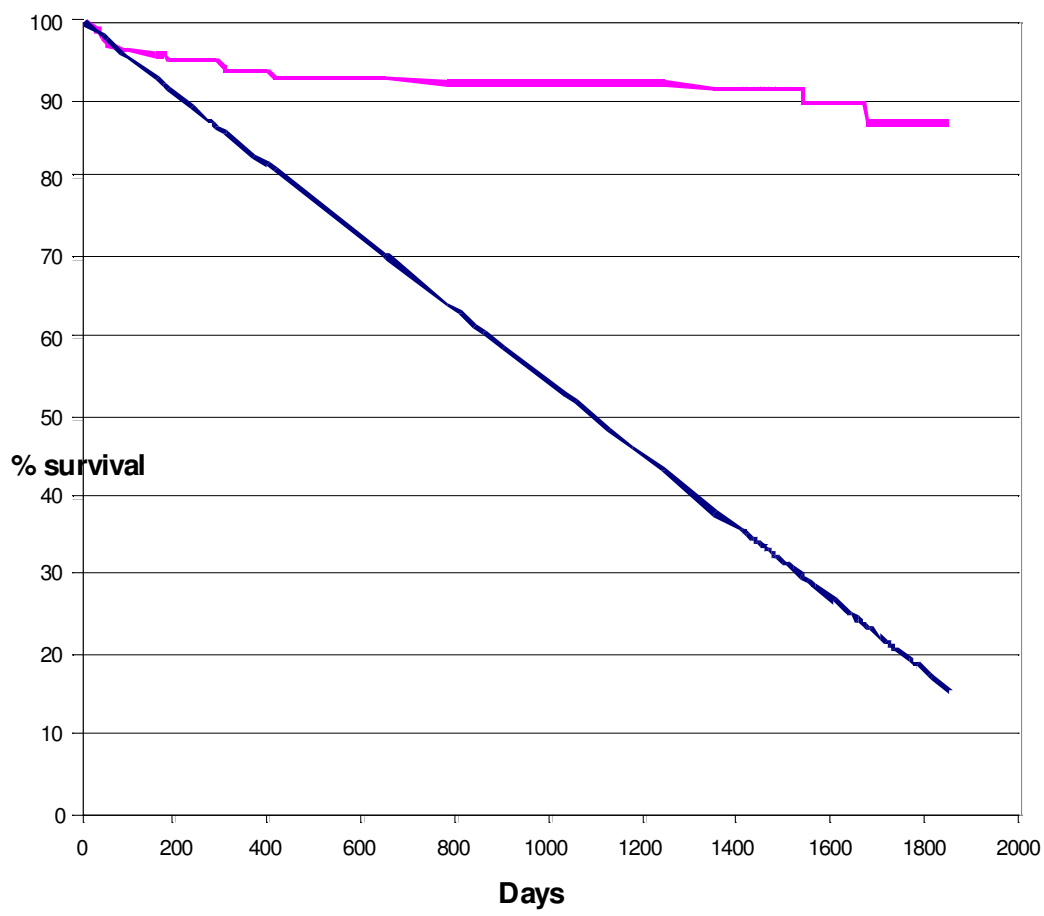

- Cohort with no treatment — SWAA cohort 
Table 1 : Main characteristics of the cohort

\begin{tabular}{|l|r|l|l|}
\cline { 2 - 4 } \multicolumn{1}{l|}{} & \multicolumn{1}{|c|}{ Mean } & Median & \multicolumn{1}{c|}{ Range } \\
\hline Female/male ratio & $4 / 1$ & Not applicable & Not applicable \\
\hline Age (years) & 43 & 45 & $10-64$ \\
\hline Date of ART initiation & December 2003 & February 2004 & $\begin{array}{l}\text { February } 2003- \\
\text { April } 2004\end{array}$ \\
\hline $\begin{array}{l}\text { Treatment duration (years, as of } \\
\text { February 2008) }\end{array}$ & 3.6 & & $0.1-5.1$ \\
\hline
\end{tabular}


Table 2 : Age distribution of the cohort

\begin{tabular}{|l|r|r|r|}
\hline Age group (years) & \multicolumn{1}{|c|}{$\begin{array}{c}\text { Number of } \\
\text { male } \\
\text { patients }\end{array}$} & $\begin{array}{c}\text { Number of } \\
\text { female } \\
\text { patients }\end{array}$ & $\begin{array}{c}\text { Total } \\
\text { number of } \\
\text { patients }\end{array}$ \\
\hline $\mathbf{5 - 1 4}$ & 1 & 0 & 1 \\
\hline $\mathbf{1 5 - 2 9}$ & 4 & 12 & 16 \\
\hline $\mathbf{3 0 - 4 4}$ & 11 & 60 & 71 \\
\hline $45-59$ & 10 & 47 & 57 \\
\hline $\mathbf{6 0 - 6 9}$ & 0 & 4 & 4 \\
\hline Total & $\mathbf{2 6}$ & $\mathbf{1 2 3}$ & $\mathbf{1 4 9}$ \\
\hline
\end{tabular}


Table 3 : Annual per patient costs for cost items estimated from the NGO's data

\begin{tabular}{|c|c|c|c|}
\hline Cost item & $\begin{array}{l}\text { Unit cost } \\
(2007 \\
\text { constant } \\
\text { US\$ per } \\
\text { year })\end{array}$ & $\begin{array}{c}\text { Mean quantities } \\
\text { utilised per patient } \\
\text { and per year } \\
\text { (number of } \\
\text { utilizations per } \\
\text { patient and per } \\
\text { year) }\end{array}$ & $\begin{array}{l}\text { Annual per patient } \\
\text { cost }(2007 \text { constant } \\
\text { US\$ per year) }\end{array}$ \\
\hline Out-patient visits & 5.0 & 14.00 & 71 \\
\hline Pharmacy & 1.1 & 21.20 & 23 \\
\hline Laboratory tests & 6.7 & 19.98 & 133 \\
\hline VCT & 3.7 & 0.07 & 0.3 \\
\hline Adherence counselling & 24.4 & 2.37 & 58 \\
\hline Day hospital & 11.5 & 0.16 & 2 \\
\hline Psychological and social support & 40.7 & 1.00 & 41 \\
\hline Food support & 101 & 1.00 & 101 \\
\hline Subtotal & & & 429 \\
\hline
\end{tabular}


Table 4 : Annual cost per patient of CD4 count and VL tests

\begin{tabular}{|l|r|r|}
\cline { 2 - 3 } \multicolumn{1}{c|}{} & \multicolumn{1}{c|}{$\begin{array}{c}\text { CD4 count (2007 } \\
\text { constant US\$ per year) }\end{array}$} & $\begin{array}{c}\text { VL (2007 constant US\$ } \\
\text { per year) }\end{array}$ \\
\hline Reagents & 17.3 & 23.7 \\
\hline Other indirect materials & 0.4 & 2.0 \\
\hline Total unit costs & 17.7 & 25.7 \\
\hline Utilisation frequency per pt year & 1.07 & 0.53 \\
\hline Annual cost per patient & 19 & $\mathbf{1 4}$ \\
\hline
\end{tabular}


Table 5 : Antiretroviral drug regimens among patients in the sample in February 2008

\begin{tabular}{|c|c|c|c|}
\hline Regimen & $\begin{array}{c}\text { Number of } \\
\text { patients }\end{array}$ & Share (\%) & $\begin{array}{l}\text { Annual cost at } 2007 \\
\text { prices }(2007 \text { constant } \\
\text { US\$ per year) }\end{array}$ \\
\hline $\mathrm{ZDV}+3 \mathrm{TC}+\mathrm{NVP}$ & 37 & $25 \%$ & 165 \\
\hline$d 4 T+3 T C+N V P$ & 36 & $24 \%$ & 83 \\
\hline ZDV+3TC+EFV & 25 & $17 \%$ & 268 \\
\hline d4T+3TC+EFV & 25 & $17 \%$ & 93 \\
\hline 3TC+ddI+NVP & 6 & $4 \%$ & 176 \\
\hline $\mathrm{ZDV}+3 \mathrm{TC}+\mathrm{ABC}$ & 4 & $3 \%$ & 510 \\
\hline $\mathrm{d} 4 \mathrm{~T}+3 \mathrm{TC}+\mathrm{ABC}$ & 4 & $3 \%$ & 446 \\
\hline d4T+ddI+EFV & 3 & $2 \%$ & 305 \\
\hline $\mathrm{ZDV}+3 \mathrm{TC}+\mathrm{NFV}$ & 3 & $2 \%$ & 858 \\
\hline Others (IDV, LPV/r...) & 6 & $4 \%$ & Not applicable \\
\hline Total & 149 & $100 \%$ & Not applicable \\
\hline
\end{tabular}


Table 6 : Annual antiretroviral drug cost per patient

\begin{tabular}{|l|r|r|r|r|r|r|}
\cline { 2 - 6 } \multicolumn{1}{c|}{} & 2003 & 2004 & 2005 & 2006 & 2007 & 2008 \\
\hline $\begin{array}{l}\text { Antiretroviral drug cost per patient } \\
(2007 \text { constant US\$ per year) }\end{array}$ & 811 & 612 & 464 & 297 & 262 & 242 \\
\hline
\end{tabular}


Table 7: Annual cost of drugs for OI or ART side effect treatments

\begin{tabular}{|c|c|c|c|}
\hline & $\begin{array}{l}\text { Cost per episode } \\
(2007 \text { constant } \\
\text { US\$ per episode) }\end{array}$ & $\begin{array}{c}\text { Frequency } \\
\text { (episode per } \\
\text { patient per year) }\end{array}$ & $\begin{array}{l}\text { Annual cost per } \\
\text { patient (2007 } \\
\text { constant US\$ per } \\
\text { year) }\end{array}$ \\
\hline Cryptococcal meningitis & 31.1 & 0.2 & 5.2 \\
\hline Intestinal parasitis & 19.2 & 0.1 & 2.0 \\
\hline Otitis media & 42.2 & 0.1 & 1.3 \\
\hline Peripheral neuropathy & 3.0 & 0.4 & 1.1 \\
\hline Tuberculosis & 11.5 & 0.1 & 1.0 \\
\hline Other diseases & \multicolumn{2}{|c|}{ Not applicable } & 1.2 \\
\hline Total annual cost per patient & \multicolumn{2}{|c|}{ Not applicable } & 11.8 \\
\hline
\end{tabular}


Table 8 : Total cost of treatment since 2003

\begin{tabular}{|l|r|r|r|r|r|r|}
\cline { 2 - 7 } & $\mathbf{2 0 0 3}$ & $\mathbf{2 0 0 4}$ & 2005 & 2006 & 2007 & 2008 \\
\hline $\begin{array}{l}\text { Treatment cost excl. ART drugs (2007 } \\
\text { constant US\$) }\end{array}$ & 494 & 494 & 494 & 494 & 494 & 494 \\
\hline Antiretroviral drug cost (2007 constant US\$) & 811 & 612 & 464 & 297 & 262 & 242 \\
\hline Total treatment cost (2007 constant US\$) & 1,305 & 1,106 & 958 & 791 & 756 & 736 \\
\hline
\end{tabular}


The cost effectiveness of integrated care for people living with HIV including antiretroviral treatment in a primary health care centre in Bujumbura, Burundi

Table 9 : Number of DALYs averted by the ART delivered by SWAA-Burundi

\begin{tabular}{|l|r|r|r|}
\cline { 2 - 4 } \multicolumn{1}{c|}{} & \multicolumn{1}{c|}{ YLL } & \multicolumn{1}{c|}{ YLD } & \multicolumn{2}{c|}{ DALYs lost } \\
\hline Sample cohort & 250 & 69 & 319 \\
\hline Modelled control cohort & 2,173 & 58 & $\mathbf{1 , 9 1 2}$ \\
\hline Total number of DALYs averted & & & $\mathbf{1 3}$ \\
\hline Number of DALYs averted per patient & & & \\
\hline
\end{tabular}

